\title{
Ephedra alata extracts exhibits anti-obesity, anti- hyperlipidaemic, anti-hyperglycemia, anti-antipyretic and analgesic effects through the inhibition of lipase, $a$-amylase and inflammation
}

\section{Mohamed Tiss}

Laboratory of Bioresources: Integrative Biology a

\section{Zoubeida Souiy}

igher Institute of Technological Studies, Ksar H

Mohamed Boujbiha

Laboratory of Bioresources: Integrative Biology an

Lotfi Achour

Laboratory of Bioresources: Integrative Biology an

Khaled Hamden ( $\square$ khaled.hamden@yahoo.fr)

Laboratory of Bioresources: Integrative Biology and Exploiting, Higher Institut https://orcid.org/00000001-5651-3962

\section{Research}

Keywords: Ephedra alata, obesity, diabetes, pain, fever, key enzymes

Posted Date: May 13th, 2020

DOI: https://doi.org/10.21203/rs.3.rs-23622/v1

License: (c) (i) This work is licensed under a Creative Commons Attribution 4.0 International License.

Read Full License 


\section{Abstract}

In this present study, phytochemical screening, anti-obesity, anti- antipyretic and analgesic effect of Ephedra alata (EA) extracts were evaluated. Results of this study showed that the methanol EA extract (MEAE) had a stronger inhibition activity on key enzyme related to obesity as lipase (IC50 $=1.296 \mathrm{mg} / \mathrm{ml}$ ) as compared to water and ethyl acetate extracts ( with $\mathrm{IC}_{50}=1.639$ and 1.897 respectively). Also results revealed that ethyl acetate extract depicted high activity toward key enzyme related to hyperglycemia as a-amylase (IC50 $=0.284 \mathrm{mg} / \mathrm{mL}$ ) while water and methanol extracts showed good to moderate inhibitory activity $\left(\mathrm{IC}_{50}=1,525\right.$ and $1,103 \mathrm{mg} / \mathrm{ml}$ respectively). In HFFD rats, the administration of MEAE at $200 \mathrm{mg} / \mathrm{kg}$ inhibited key enzyme related to fat digestion and absorption as lipase in the intestine, pancreas and serum by 53,40 and $53 \%$ respectively,which leads to decrease in body weight by $20 \%$ and also modulation of lipid profile. In addition, the administration of MEAE to HFFD-rats exerts an inhibitory effect on a-amylase activity in the intestine, pancreas and serum by 43,26 and $46 \%$ respectively and this leads to decrease in blood glucose level by $35 \%$. Also, MEAE exert antipyretic and analgesic activities. This study demonstrates for the first time that MEAE are efficient in preventing obesity and hyperglycemia and liver toxicity. This data generated during study shows antipyretic and analgesic activities of MEAE.

\section{Introduction}

Today, Obesity caused by imbalance between energy intake and consumption is one of the main public health problems in the world. It is a risk factor various diseases such as type 2 diabetes, some forms of cancer, hypertension, stroke, and mental health disorders [1, 2]. Also, persistent hyperlipidemia and hyperglycaemia induces the development of variety of complications and disorders as pain, inflammation and many others perturbations and diseases [3]. The reducing of carbohydrates and lipids absorption from diet may improve the situation. a-glucosidase, a-amylase, and pancreatic lipase are enzymes secreted by lumen of small intestine, pancreas, and salivary glands [4]. Also, hyperglycemia and obesity a diet rich in fats and sedentary life-way contributes the occurrence of type 2 diabetes, obesity, hyperlipidemia, cardiovascular diseases and inflammation [4,5]. The anti-inflammatory drugs including aspirin, indomethacin, naproxen and ibuprofen, are considered as antipyretic, analgesic and antiinflammatory medications with activity related to the inhibition of the cyclooxygenase (COX) enzymes [6]. Although these anti-inflammatory drugs can help treat many inflammatory diseases, they have side effects: NSAIDs cause serious gastrointestinal injury and hepatotoxicity, and GCs cause sodium retention, obesity and osteoporosis; these result in serious health problems [7]. Therefore, there is an ongoing search for natural digestive enzyme inhibitors with fewer side effects for prevention or mitigation the symptom of obesity or diabetes. Previous researches have shown that some types of tea exhibited pronounced inhibitory effects towards the activities of a-amylase, lipase and inflammation $[8,9]$. At present, many treatments involving the use of medicinal plants have been recommended, since most contain compounds with antidiabetic, anti-inflammatory, anti-pyretic and analgesic effects and with low indices of toxicity $[5,10,11]$. Plants are huge source of bioactive secondary metabolites such as 
glycosides, saponins, flavonoids, steroids, tannins, alkaloids and terpenes, which act as strong antioxidant to protect body from oxidative damage [12]. These secondary metabolites have shown several biological activities such as antibacterial, antioxidant, anti-inflammatory, antiulcer, analgesic and also used for the treatment of diabetes [12].

Ephedra alata was an important source of several pharmaceutical compounds such of cardiac glycosides, reducing sugars, flavonoids, phenolic compounds, and alkaloids; and as Significant medicinal properties of this genus were reported such as antimicrobial, antioxidant, antidiabetic, hepatoprotective, cardiovascular, and anticancer effects [13-16]. Previous studies have reported that Ephedra Herb may have applications in cancer therapy and suppressed cancer metastasis by inhibiting cancer cell motility $[17,8,9]$ and prevented hepatocyte growth factor (HGF)-induced cancer cell motility by inhibiting phosphorylation of the c-Met receptor [17].

No evidence has, however, been provided on the effect of Ephedra alata fractions on the obesity, type 2 diabetes, fever and pain. Accordingly, the present study was undertaken to evaluate, in the first time, the anti-obesity, anti-hyperlipidemia, anti-hyperglycemia, anti-pyretic and analgesic effects of Ephedra alata extracts.

\section{Materials And Methods}

\section{Plant material and extracts preparation}

Ephedra alata were collected from Gafsa (Tunisia) during the last week of May 2018. The leaves of Ephedra alata were dried at room temperature. The dried plant parts were ground to a fine powder using a laboratory mill. Each of the powdered parts $(10 \mathrm{~g})$ was separately extracted with ethyl acetate, and methanol in a Soxhlet apparatus for $6-8 \mathrm{~h}$. All the concentrated extracts were vacuum dried at $40^{\circ} \mathrm{C}$ using a rotary vacuum evaporator. The water extracts were obtained by boiling powdered samples with $100 \mathrm{ml}$ distilled water for $15 \mathrm{~min}$. The water extracts were filtered and then lyophilized $\left(-80^{\circ} \mathrm{C}, 48 \mathrm{~h}\right)$. All the extracts were stored at $+4{ }^{\circ} \mathrm{C}$ in dark until further use.

\section{a-amylase inhibition activity in vitro}

a-Amylase inhibition method was carried out with minor modification [18]. The enzyme solution was equipped by melting a-amylase in $20-\mathrm{mM}$ phosphate buffer $(6.9 \mathrm{pH})$ at concentration $0.5 \mathrm{mg} / \mathrm{ml}$. The reaction mixture composed of $1 \mathrm{ml}$ of each extract at various concentrations ranged from $100 \mu \mathrm{g}$ to $5 \mathrm{mg} / \mathrm{ml}$ was added to $1 \mathrm{ml}$ of enzyme solution $(12 \mathrm{U} / \mathrm{ml})$ solution; mixed incubated at $25^{\circ} \mathrm{C}$ for 10 minutes. After that, $1-\mathrm{ml}$ starch $(0.5 \%)$ was added to the solution and kept warm again at $25^{\circ} \mathrm{C}$ for 10 minutes. The reaction stopped when 2-ml di-Nitro salicylic acid was added (DNS color reagent), then heating the reaction mixture for 5 minutes in a water bath. Then cooled and the absorbance at $565 \mathrm{~nm}$ was measured using spectrophotometer. Acarbose was used with the same concentrations as a control. The experiment was carried out in triplets. 


\section{Pancreatic lipase inhibition assay in vitro}

In this assay, the porcine pancreatic lipase activity was measured using p-nitrophenyl butyrate (NPB) as a substrate. Lipase solution $(100 \mu \mathrm{g} / \mathrm{ml})$ was prepared in a $0.1 \mathrm{mM}$ potassium phosphate buffer $(\mathrm{pH} 6.0)$. In this assay, extracts with different concentrations ranged from $100 \mu \mathrm{g}$ to $5 \mathrm{mg} / \mathrm{ml}$ were pre-incubated with $100 \mu \mathrm{g} / \mathrm{ml}$ of lipase for 10 minutes at $37^{\circ} \mathrm{C}$. The reaction was then started by adding $0.1 \mathrm{ml} \mathrm{NPB}$ substrate. The amount of $\mathrm{p}$-nitrophenol released in the reaction was measured using Multi-plate Reader after incubation at $37^{\circ} \mathrm{C}$ for 15 minutes. Atorvastatin was used with the same concentrations as a control. Each experiment was performed in triplets. The data were expressed as percentage inhibition, which was calculated using the formula, Inhibitory activity $(\%)=(1-A s / A c) \times 100$ where, As is the absorbance in the presence of the test substance and Ac is the absorbance of control.

\section{Antipyretic activity}

The Swiss albinos mice were randomly divided into four groups each consisting of five animals. All the groups were first treated with baker yeast (Saccharomyces cerevisiae) ( $3 \mathrm{~mL} / \mathrm{kg}$ of $10 \%$ suspension subcutaneous) for fever induction. After $24 \mathrm{~h}$ of yeast administration, Group 1 animals were treated with distilled water and served as negative control. Group 2 animals were treated with paracetamol by oral administration and taken as positive control. Group 3, 4 and 5 animals were treated with MEAE at doses 100, 200 and $400 \mathrm{mg} / \mathrm{Kg}$ bw daily. Rectal temperature was measured with digital thermometer.

\section{Analgesic activity}

forty four hours before the experiment, Swiss male albino mice (20-25 g, $n=6$ per treatment group) were randomly divided into five groups. group 1: negative control (distilled water, $10 \mathrm{ml} / \mathrm{kg}$ ). Another group served as a positive control (lysine acetylsalicylic acid (ASL) at $200 \mathrm{mg} / \mathrm{kg}$ ), while the other three groups received MEAE at doses 100,200 and $400 \mathrm{mg} / \mathrm{kg}$ respectively. All the drugs were injected intraperitoneally (i.p.). $50 \mathrm{~min}$ later, the mice received acetic acid $(10 \mathrm{ml} / \mathrm{kg}$, bw) by injection, which induced the writhing reflex. The number of writhes was counted cumulatively over a period of $20 \mathrm{~min}$ by an observer unaware of the treatment groups.

\section{Anti-obesity, anti-hyperlipidemic anti-hyperglycemia activities in HFFD-rats}

A total of 32 were subdivided into four experimental groups and treated in the following way. Male rats were randomly divided into four groups, eight rats in each group. $C$ group: Control rats fed on a standard diet (control diet group, CD); HFFD group: Rats fed on high-fat-high-fructose diet (HFFD); HFFD + MEAE group: Rats fed on HFFD and received additional $100 \mathrm{mg} / \mathrm{kg}$ of body weight of MEAE in a volume of $1 \mathrm{ml}$ water during 12-weeks daily; and HFFD + Atorv group: Rats fed on HFFD and received additional $5 \mathrm{mg} / \mathrm{kg}$ of body weight of a commercial atorvastatin daily by gastric gavage route. The animals were sacrificed by decapitation three months after. The serum was obtained from trunk blood collected after decapitation. Plasma was immediately separated by centrifugation at $4^{\circ} \mathrm{C}$ and $1,500 \times g$ for 15 minutes. The samples were stored at $-80^{\circ} \mathrm{C}$ until further used. The intestine and pancreas of each rat was excised 
and the lumen was flushed out several times with $0.9 \% \mathrm{NaCl}$. The scraped-off mucosal tissue was pooled, homogenized, and centrifuged at $4,000 \times \mathrm{g}$. and the supernatant was frozen until use in further enzymatic assays.

\section{Analytical Methods}

The activity of intestinal a-amylase was determined by measuring the amount of glucose released from CNPG3 substrate (Kits, Biolabo, France, ref 99223). The activities of intestinal lipase were determined by measuring the amount of fatty acids released from 1.2 diglycerides substrate (Kits, Biolabo, France, ref 99881). The levels of total-cholesterol, LDL-C, and HDL-C in the serum were measured using commercial kits from Biomagreb (Refs 20111, 20113 and 201132). The serum glucose level in the serum was measured by measuring the amount of red quinoneimine released from oxidation of glucose substrate (Kits, Biolabo, France, ref 80009).

\section{Statistical Analysis}

Data are presented as means $\pm S D$. Determinations were performed from ten animals per group. The differences were examined using one-way analysis of variance (ANOVA) and Fisher test (Stat View) and the significance value was accepted at $p \leq 0.05$.

\section{Results}

\section{Inhibition of lipase activity in vitro}

The dose-dependent inhibition of lipase by Ephedra alata extracts (Table 1) shows the potential ability of MEAE to control obesity and hyperlipidemia. The methanol extract $(1.296 \pm 0.13 \mathrm{mg} / \mathrm{mL})$ had significantly higher lipase inhibitory activity than the water and Ethyl acetate extracts $\left(\mathrm{IC}_{50}=1.639 \pm 0.15\right.$ and $1.897 \pm 0.17 \mathrm{mg} / \mathrm{mL}$ respectively).

\section{Inhibition of a-amylase activity in vitro}

The inhibition of a-amylase activity by Ephedra alata extracts and positive control (Acarbose) are shown in Table 1. The highest activity was determined for the Ethyl acetate extract from leaves of Ephedra alata, (IC50 $=0.284 \pm 0.05 \mathrm{mg} / \mathrm{mL}$ ). The IC50 values of the methanol and water extracts from Ephedra alata leaves were , $103 \pm 0.08 \mathrm{mg} / \mathrm{mL}$ and, $525 \pm 0.13 \mathrm{mg} / \mathrm{mL}$, respectively.

\section{Intestine, pancreas and serum lipase activity and serum lipid concentration and body weight}

Fig. 1 indicates that, when compared to normal rats, the intestine, pancreas and serum lipase activity in the diabetic rats underwent a potent increase in the intestine, pancreas and serum of 196, 132 and $264 \%$ respectively. The increase in lipase activity stimulated lipid absorption and, consequently, led to remarkable increases in the TC and LDL-C concentrations in the plasma, which, compared to that of the normal rats, reached 61 and $65 \%$, respectively. This increase of lipid absorption and accumulation in various bodies leads to increase of body weight by about $16 \%$. The administration of MEAE to HFFD-rats 
was, however, observed to have reverted the activity of lipase in intestine, pancreas and serum back by 53,40 and $53 \%$ respectively. This supplement was also observed to bring about a considerable decrease of 39 and $31 \%$ in the TC and LDL-C; and increase of $14 \%$ in the HDL-C concentrations in the plasma, respectively. Moreover, while obesity was noted to induce a decrease in the body weight by $20 \%$ after MEAE supplement as compared to untreated HFFD-rats.

\section{Intestine, pancreas and serum a-amylase activity and serum glucose concentration}

The findings indicated that compared to the control, there was a significant increase in the activity of aamylase by 158,88 and $154 \%$ respectively in the intestine, pancreas and serum of HFFD-rats. However, after the administration of MEAE to HFFD-rats, a considerable reduction in intestine, pancreas and serum a-amylase activity was observed, which leads to a decrease in blood glucose level by $35 \%$ as compared to untreated HFFD-rats (Fig.2).

\section{Evaluation of the anti-pyretic activity of Ephedra alata extract}

The effect of Ephedra alata extracts on yeast induced pyrexia has been shown in Table 4. This study showed that administration of Saccharomyces cerevisiae at dose $3 \mathrm{~mL} / \mathrm{kg}$ of $10 \%$ suspension by subcutaneous injection methods stimulated increase in body temperature and induced fever. From the results (Table 6), it was observed that, experimental mice showed a marked increase in rectal temperature from $37^{\circ} \mathrm{C}$ to about $39^{\circ} \mathrm{C}, 24 \mathrm{~h}$ after Yeast injection. However, the treatment with extracts at dose of $100 \mathrm{mg} / \mathrm{kg}$ and paracetamol at dose of, $100 \mathrm{mg} / \mathrm{kg}$ decreased body temperature of yeast induced mice in a dose-dependent manner. The antipyretic effect started as from the second hour and the effect was maintained for $4 \mathrm{~h}$, after administration of the extract. The results obtained from both standards and extracts treated groups were compared with the control group. A significant reduction in the yeast elevated rectal temperature was observed in the test drug.

\section{Evaluation of the analgesic activity of Ephedra alata extract}

The number of cramps performed by the animal following intraperitoneal injection of $3 \%$

acetic acid and the percentage of inhibition of cramp, at different concentrations of Ephedra alata extract are presented in the table 3 . It can be seen that the highest doses assayed caused a significant diminution effect of cramp in a dose-dependent manner as compared to control. The mean of inhibition was $33.46,49.6$ and $55.86 \%$ at 100,200 and $400 \mathrm{mg} / \mathrm{kg}$ respectively.

\section{Discussion}

Pancreatic lipase (a key enzyme in the small intestine) is able to hydrolyze and absorb triglyceride. Thus, one of the approaches to prevent obesity and prevention of triglyceride absorption is inhibition $r$ decreasing lipase activity [19]. The excessive fat in diet would be stored in the body in the form of fat in adipose tissue [20-22]. Therefore, lipase inhibition is one of the most widely studied mechanisms used to limit triacylglycerol absorption, leading to a decrease in caloric yield and weight loss [3, 23]. Moreover, 
inhibition of lipase determines the potential efficacy of natural products as anti-obesity agents and beneficial for the regulation of metabolic disorders [4, 24-26]. The effect of Ephedra alata extract on porcine pancreatic lipase activity is shown in Table 1. The IC50 value of Ethyl acetate, water and methanol extracts were.8, 1.6 and $1.2 \mathrm{mg} / \mathrm{ml}$ respectively; while this value for atorvastatin (an inhibitor of pancreatic lipase used as an anti-hyperlipidemic agent) was $0.97 \mathrm{mg} / \mathrm{ml}$. In HFFD-rats, this study showed that administration of MEAE decreased the activity of lipase in intestine, pancreas and serum back by 53 , 40 and $53 \%$ respectively. This inhibition in the lipase activity leads to a significant decrease in TC and LDL-C; and increase in HDL-C in HFFD-rats treated with MEAE as compared to untreated rats and leading to the decreased of body weight as anti-obesity activity. One of the probable reasons for it is the higher content of polyphenolic and flavonoid compounds in methanol fraction of Ephedra alata. In fact, Ziani et al [27] have reported that The hydro-methanol crude extract contained the maximum number of phenolic compounds (22 compounds among the 24 compounds detected) which the most concentrated was quinic acid Apigenin-6,8-C-dihexoside, Erydictiol-0-hexoside, Erydictiol-0-hexoside, Apigenin-8-C-glucoside, Quercetin-3-0-glucuronide, Rosmarinic acid hexoside. Amakura et al. ${ }^{28}$ [28] reported on the main individual polyphenols in EA (cinnamic acid, syringin, catechin, epicatechin, symplocoside, pollenitin B, herbacetin 7-0-glucoside, kaempferol 3-0-rhamnoside 7-0-glucoside, and isovitexin 2-0-rhamnoside).

Obesity has been proven to lead to many complications including cardiovascular diseases, chronic kidney failure, foot ulcers, and type 2 diabetes. Diabetes one of the most challenging chronic disorder of the 21 st century that alters carbohydrate, protein, and fat metabolisms. It is characterized by chronic hyperglycemia, caused abnormal insulin secretion or insulin action or both [12]. In fact, The rate of carbohydrate and lipid digestion can influence or adversely affect postprandial glycaemia, weight gain, and obesity, particularly in people at risk of T2D. Hence, limiting carbohydrate and lipid digestion is considered a therapeutic approach to control hyperglycemia, weight gain, and obesity. Results of this study showed that Ethyl acetate, water and methanol extracts of Ephedra alata extracts inhibited aamylase activity with IC50 $0.28,1.5$ and $1.1 \mathrm{mg} / \mathrm{ml}$ respectively. In HFFD-rats administration of MEAE significantly decreased the a-amylase activity in intestine, pancreas and serum; and consequently decrease in blood glucose level of $35 \%$ as compared to untreated HFFD-rats. The potent inhibitory effect of the a-amylase may be influenced by the abundance of phenolic compounds in MEAE. It has been reported in the literature that Ephedra alata alcohol extract contain bioactive principle that may be useful in the management or prevention of diabetic complications [29, 30]. In fact, The LC-DAD-ESI/MSn profile of $\mathrm{E}$. alata was characterized by the presence of various phenolic compounds, all belonging to flavonoids class, namely five isoflavones the diazein, the Epicatechin, the rutin as well as the quercitin and flavones; and also, the presence of the myricetin derivatives, such as myricetin 3-rhamnoside [31]. These compounds have been reported to be useful in the treatment of various diseases. Herein, a very high amount of polyphenols and flavonoids in that have gastroprotective, hepatoprotective, antihyperlipidemic, anti-inflammatoire, analgesic and anti-diabetic effects....[32-36].

Fever (pyrexia) is defined as a complicated physiologic response caused by infection or aseptic stimuli. The body temperature elevation occurs when PGE2 accumulate in the hypothalamus pre-optic region. 
The neurons firing rate in the hypothalamus control thermoregulation and is usually altered by increased synthesis of PGE2. Research has reported that most antipyretic drugs exert their action by inhibiting cyclooxygenase enzymatic activity and consequently reducing PGE2 levels within the hypothalamic region [37]. This study was carried out to evaluate the antipyretic effects of MEAE in mice. The This findings from the present study were in agreement with other studies on antipyretic potential medicinal plants in animal models. Previous studies have reported that Ephedra plants contents alkaloids including ephedrine, pseudoephedrine, and ephedroxane, had potent anti-inflammatory activity in vivo. This antiinflammatory effect was likely due to the inhibition of prostaglandin E2 biosynthesis[38]. Another study showed that administration of methanol extract of Ephedra alata to rats could suppress the INFY level, one of the inflammatory cytokine, plays an important role in the activation of innate and adaptive immune system signaling pathways in the tumor context [13].

In mice, acetic acid contributes to the release of arachidonic acids from the phospholipid membrane and synthesize PG via the cyclo-oxygenase. Acute inflammation induced by acetic acid is directly related to increased levels of prostaglandin E2 and prostaglandin (PGF2a), consequently increase of bradykinin, serotonin, and histamine secretion, which are involved for the stimulation of the central nociceptive neurons[39]. Any substance causing inhibition of acetic acid-induced writhing may have antiinflammatory and analgesic effects [39]. This study was carried out to evaluate the antipyretic effects of MEAE in mice. This study showed that MEAE to acetic-acid treated rats caused a significant diminution effect of cramp in a dose-dependent manner as compared to control. The findings from the present study were in agreement with other studies on analgesic and anti-inflammatory actions of Ephedra alata in animal models. Similar work by Hyuga et al. [40] demonstrated analgesic effects of bioactives drugs contents in Ephedra methanolic extract ephedrine, pseudoephedrine, and ephedroxane, in acetic acidinduced pain. A study by Hanawa et al. [41] demonstrated that herbacetin, a component of Ephedra Herb, suppressed the formalin-induced pain. Ephedra Herb extract and EFE reduced paw-licking time in a dosedependent manner during the second phase of the formalin test.

\section{Conclusion}

The aims of the present study, then are to evaluate the effects of the Ephedra alata extracts obesity, hyperlipidemia hyperglycemia, pain and fever. Results the current study demonstrate that methanol extract of this plant exhibited promising beneficial effects by prevention and improvement of obesity, hyperlipidemia, hyperglycemia, pain and fever.

\section{Abbreviations}

\section{EA}

Ephedra alata

HFFD

high-fat fructose diet

HDL-C 
high-density lipoprotein cholesterol

LDL-C

low-density lipoprotein-cholesterol

MEAE

methanol Ephedra alata extract

TC

total cholesterol

\section{Declarations}

\section{Ethics approval and consent to participate}

The animal studies conducted in this work followed the International Guidelines for Animal Care Directive 86/609/EEC, and was approved by the Tunisian Ethics Committee of the University of Monastir (Monastir, Tunisia) for the care and use of laboratory animals

\section{Consent for publication}

All the authors consent to the publication of the manuscript in Nutrition \& Metabolism.

\section{Availability of data and materials}

Data sharing not applicable to this article as no datasets were generated or analyzed during the current study.

\section{Competing interests}

The authors declare that they have no competing interests

\section{Funding}

This research was supported by the Tunisian Ministry of Higher Education and Scientific Research and Technology and the Tunisian Ministry of public heath.

\section{Authors' contributions}


T.M and S.Z performed the experiments, analyzed the data and wrote the paper. L.A and K.H analyzed the data, conceived and designed the experiments.

\section{Acknowledgements}

The authors would like to express their gratitude to Laboratory of Biochemistry, CHU Fattoma Bourguiba, University of Monastir, Tunisia.

\section{References}

1. Su $\mathrm{H}$, et al. In vitro and in vivo inhibitory activity of taxifolin on three digestive enzymes. Int J Biol Macromol. 2020;150:31-7.

2. Li H, et al. Phenolic-enriched blueberry-leaf extract attenuates glucose homeostasis, pancreatic $\beta$-cell function, and insulin sensitivity in high-fat diet-induced diabetic mice. Nutr Res. 2020;73:83-96.

3. Spínola V, Llorent-Martínez EJ, Castilho PC. Inhibition of a-amylase, a-glucosidase and pancreatic lipase by phenolic compounds of Rumex maderensis (Madeira sorrel). Influence of simulated gastrointestinal digestion on hyperglycaemia-related damage linked with aldose reductase activity and protein glycation. LWT. 2020;118:108727.

4. Abdel-Hady H, El-Wakil EA, Morsi EA. Characterization of ethyl acetate and methanol extracts of Commiphora myrrha and evaluating in vitro anti-diabetic and anti-obesity activities. Journal of Applied Pharmaceutical Science. 2019;9(09):038-44.

5. Spínola V, Llorent-Martínez EJ, Castilho PC. Inhibition of a-amylase, a-glucosidase and pancreatic lipase by phenolic compounds of Rumex maderensis (Madeira sorrel). Influence of simulated gastrointestinal digestion on hyperglycaemia-related damage linked with aldose reductase activity and protein glycation. LWT, 2020. 118.

6. Hudson $\mathrm{WH}$, et al. Cryptic glucocorticoid receptor-binding sites pervade genomic NF-kB response elements. Nature communications. 2018;9(1):1-13.

7. Ou Z, et al. Anti-inflammatory effect and potential mechanism of betulinic acid on $\lambda$-carrageenaninduced paw edema in mice. Biomed Pharmacother. 2019;118:109347.

8. Feng L, et al., Chemical profile changes during pile fermentation of Qingzhuan tea affect inhibition of a-amylase and lipase. Scientific Reports, 2020. 10(1).

9. Ghasemian M, Owlia S, Owlia MB, Review of anti-inflammatory herbal medicines. Advances in pharmacological sciences, 2016. 2016.

10. Franco RR, et al., Antidiabetic potential of Bauhinia forficata Link leaves: a non-cytotoxic source of lipase and glycoside hydrolases inhibitors and molecules with antioxidant and antiglycation properties. Biomedicine and Pharmacotherapy, 2020. 123.

11. Joshi DR, Shrestha AC, Adhikari N. A Review on Diversified Use of The King Of Spices: Piper Nigrum (Black Pepper). International Journal of Pharmaceutical Sciences Research. 2018;9(10):4089-101. 
12. Upreti A, et al. Evaluation of a-amylase, lipase inhibition and in-vivo pharmacological activities of Eucalyptus camaladulensis Dehnh leaf extract. Journal of Traditional Complementary Medicine. 2019;9(4):312-8.

13. Sioud F, et al., Methanolic extract of Ephedra alata ameliorates cisplatin-induced nephrotoxicity and hepatotoxicity through reducing oxidative stress and genotoxicity. Environmental Science and Pollution Research, 2020: p. 1-10.

14. Nakamori S, et al., Therapeutic and analgesic effects of ephedrine alkaloids-free Ephedra Herb extract on complete Freud's adjuvant-induced arthritis model mouse. Planta Medica, 2019. 85(18): p. SL A-04.

15. Nakamori S, et al. Analgesic Effects of Ephedra Herb Extract, Ephedrine Alkaloids-Free Ephedra Herb Extract, Ephedrine, and Pseudoephedrine on Formalin-Induced Pain. Biological Pharmaceutical Bulletin. 2019;42(9):1538-44.

16. Lamine JB, et al. A-amylase and a-glucosidase inhibitor effects and pancreatic response to diabetes mellitus on wistar rats of ephedra alata areal part decoction with immunohistochemical analyses. Environ Sci Pollut Res. 2019;26(10):9739-54.

17. Hyuga $S$, et al. Ephedrine alkaloids-free Ephedra Herb extract: a safer alternative to ephedra with comparable analgesic, anticancer, and anti-influenza activities. J Nat Med. 2016;70(3):571-83.

18. Gayathri G, Gayathri M. Preliminary qualitative phytochemical screening and in vitro hypoglycemic potential of Acanthus ilicifolius and Evolvulus emerginatus. Int J Pharm Pharm Sci. 2014;6(6):3625.

19. Noorolahi Z, et al., Tannin fraction of pistachio green hull extract with pancreatic lipase inhibitory and antioxidant activity. Journal of Food Biochemistry, 2020.

20. Tiss $M$, et al. Fermented soy milk prepared using kefir grains prevents and ameliorates obesity, type 2 diabetes, hyperlipidemia and Liver-Kidney toxicities in HFFD-rats. Journal of Functional Foods. 2020;67:103869.

21. Gutiérrez-Grijalva EP, et al. Cellular antioxidant activity and in vitro inhibition of a-glucosidase, aamylase and pancreatic lipase of oregano polyphenols under simulated gastrointestinal digestion. Food Res Int. 2019;116:676-86.

22. Mennella I, Fogliano V, Vitaglione P. Salivary lipase and a-amylase activities are higher in overweight than in normal weight subjects: Influences on dietary behavior. Food Res Int. 2014;66:463-8.

23. Peng J, et al. Study of physicochemical stability of anthocyanin extracts from black peanut skin and their digestion enzyme and adipogenesis inhibitory activities. LWT. 2019;107:107-16.

24. Moura MHC, et al. Phenolic-rich jaboticaba (Plinia jaboticaba (Vell.) Berg) extracts prevent high-fatsucrose diet-induced obesity in C57BL/6 mice. Food Res Int. 2018;107:48-60.

25. Zhang Y, et al. Analysis of chemical composition in Chinese olive leaf tea by UHPLC-DAD-Q-TOFMS/MS and GC-MS and its lipid-lowering effects on the obese mice induced by high-fat diet. Food Res Int. 2020;128:108785. 
26. Jakubczyk A, et al. Nutritional potential and inhibitory activity of bread fortified with green coffee beans against enzymes involved in metabolic syndrome pathogenesis. LWT. 2018;95:78-84.

27. Ziani BE, et al. Phenolic compounds characterization by LC-DAD-ESI/MSn and bioactive properties of Thymus algeriensis Boiss. \& Reut. and Ephedra alata Decne. Food Res Int. 2019;116:312-9.

28. Amakura Y, Characterization of Phenolic Constituents from Ephedra Herb Extract. Yakugaku zasshi: Journal of the Pharmaceutical Society of Japan, 2017. 137(2): p. 167-171.

29. Zhu X, et al., Anti-hyperglycemic and liver protective effects of flavonoids from Psidium guajava L. (guava) leaf in diabetic mice. Food Bioscience, 2020: p. 100574.

30. Cam M, et al. Bioactive properties of powdered peppermint and spearmint extracts: Inhibition of key enzymes linked to hypertension and type 2 diabetes. Food Bioscience. 2020;35:100577.

31. Ziani BEC, et al. Phenolic compounds characterization by LC-DAD- ESI/MSn and bioactive properties of Thymus algeriensis Boiss. \& Reut. and Ephedra alata Decne. Food Res Int. 2019;116:312-9.

32. Bhowmick $\mathrm{R}$, et al. In vivo analgesic, antipyretic, and anti-inflammatory potential in Swiss albino mice and in vitro thrombolytic activity of hydroalcoholic extract from Litsea glutinosa leaves. Biol Res. 2014;47(1):56.

33. Shah M, Parveen Z, Khan MR. Evaluation of antioxidant, anti-inflammatory, analgesic and antipyretic activities of the stem bark of Sapindus mukorossi. BMC Complementary Alternative Medicine. 2017; 17(1):526.

34. Chhikara N, et al., Bioactive compounds and pharmacological and food applications of Syzygium cumini - a review. Food \& Function, 2018. 9(12): p. 6096-6115.

35. de Assis POA, et al., Intestinal anti-inflammatory activity of xique-xique (Pilosocereus gounellei A. Weber ex K. Schum. Bly. Ex Rowl) juice on acetic acid-induced colitis in rats. Food \& Function, 2019. 10(11): p. 7275-7290.

36. Prateeksha, et al. The genus Usnea: a potent phytomedicine with multifarious ethnobotany, phytochemistry and pharmacology. RSC Advances. 2016;6(26):21672-96.

37. Mworia JK, et al. Antipyretic potential of dichloromethane leaf extract of Eucalyptus globulus (Labill) and Senna didymobotrya (Fresenius) in rats models. Heliyon. 2019;5(12):e02924.

38. ZHANG B-M, et al. Phytochemistry and pharmacology of genus Ephedra. Chinese journal of natural medicines. 2018;16(11):811-28.

39. Tanvir EM, et al. Antioxidant, brine shrimp lethality and analgesic properties of propolis from Bangladesh. J Food Biochem. 2018;42(5):e12596.

40. Hyuga $S$, et al. Ephedrine alkaloids-free Ephedra Herb extract: a safer alternative to ephedra with comparable analgesic, anticancer, and anti-influenza activities. Journal of natural medicines. 2016;70(3):571-83.

41. Hanawa T, et al., Multikinase inhibitors containing flavonoids or their glycosides as anticancer drugs, analgesics, and antipruritic drugs. Jpn Kokai Tokkyo Koho, JP2014129341, 2014. 


\section{Tables}

Table 1: anti-lipase and anti $\alpha$-amylase inhibition activity (\% of inhibition) of methanol, ethyl acetate and water Ephedra alata extracts (IC50, $\mathrm{mg} / \mathrm{mL})$ at different concentrations $(\mathrm{n}=3)$.

\begin{tabular}{l|cc}
\hline & \multicolumn{2}{|c}{$I C_{50}(\mathrm{mg} / \mathrm{mL})$} \\
\hline Ephedra alata & $\alpha$-amylase & Lipase \\
Water extract & $1,525 \pm 0.13$ & $1.639 \pm 0.15$ \\
Methanol extract & $1,103 \pm 0.08$ & $1.296 \pm 0.13$ \\
Ethyl acetate extract & $0.284 \pm 0.05$ & $1.897 \pm 0.17$ \\
Standard acarbose & $0.127 \pm 0.01$ & \\
Standard atorvastatin & & $0.97 \pm 0.09$ \\
& & \\
\hline
\end{tabular}

Table 2: Plasma Total-cholesterol (TC), and LDL-C, and HDL-C in HFFD-rats after 90 day of treatment by MEAE. Values are given as mean \pm SD for groups of 8 animals each. The values are statistically presented as follows:

${ }^{*} \mathrm{p}<0.05$ vs. controls at day $(0)$.

$\# \mathrm{p}<0.05$ vs. controls at day(90).

$@$ @ $<0.05$ vs. untreated HFFD-rats.

\begin{tabular}{c|cccc}
\hline & Control rats & HFFD-rats & HFFD-rats + MEAE & HFFD-rats + Atorv \\
\hline$T C(g / L)$ & $0.63 \pm 0.09$ & $0.75 \pm 0.10^{*}$ & $0.61 \pm 0.09^{\#}$ & $0.61 \pm 0.11^{\#}$ \\
$H D L-C(g / L)$ & $0.31 \pm 0.02$ & $0.21 \pm 0.09^{*}$ & $0.29 \pm 0.13^{\#}$ & $0.25 \pm 0.08^{* \# @}$ \\
$L D L-C(g / L)$ & $0.32 \pm 0.01$ & $0.54 \pm 0.11^{*}$ & $0.36 \pm 0.11^{*}$ & $0.36 \pm 0.09^{* \#} @$ \\
\hline
\end{tabular}

Table 3: Antipyretic activity of MEAE in Swiss albinos mice $(n=5)$ 


\begin{tabular}{l|llllll}
\hline & \multicolumn{5}{|l}{ Before treatment: Temperature ${ }^{\circ} \mathrm{C}$} & \multicolumn{5}{l}{ After treatment (Temperature ${ }^{\circ} \mathrm{C}$ ) } \\
\hline \multirow{3}{*}{ Negative control } & Before Yeast & $4 \mathrm{~h}$ after Yeast & $1 \mathrm{~h}$ & $2 \mathrm{~h}$ & $3 \mathrm{~h}$ & $4 \mathrm{~h}$ \\
& 37,34 & $39.14 \pm 0,13$ & $39,14 \pm 0,19$ & $39,02 \pm 0,15$ & $38,98 \pm 0,18$ & $38,9 \pm 0.16$ \\
& $\pm 0,15$ & & & & & \\
Paracetamol $100 \mathrm{mg} / \mathrm{kg}$ & 37,24 & $38,86 \pm 0,15$ & $39,16 \pm 0,33$ & $38,62 \pm 0,28$ & $38,6 \pm 0,36$ & $38,32 \pm 0,30$ \\
& $\pm 0,13$ & & & & & \\
MEAE $100 \mathrm{mg} / \mathrm{kg}$ & 36,86 & $39,10 \pm 0,15$ & $38,86 \pm 0,09$ & $38,6 \pm 0,12$ & $38,5 \pm 0,13$ & $38,12 \pm 0,11$ \\
& $\pm 0,19$ & & & & & \\
MEAE $200 \mathrm{mg} / \mathrm{kg}$ & 37,31 & $39,11 \pm 0,12$ & $38,77 \pm 0,09$ & $38,53 \pm 0,12$ & $38,37 \pm 0,14$ & $38,17 \pm 0,13$ \\
& $\pm 0,13$ & & & & & \\
MEAE $400 \mathrm{mg} / \mathrm{kg}$ & 37,19 & $39,13 \pm 0,15$ & $38,63 \pm 0,09$ & $38,47 \pm 0,12$ & $38,19 \pm 0,14$ & $38,11 \pm 0,15$ \\
& $\pm 0,17$ & & & & & \\
\hline
\end{tabular}

Table 4: analgesic activity of MEAE in Swiss albinos mice $(n=5)$

\begin{tabular}{c|ccc}
\hline Groups & Concentration $(\mathrm{mg} / \mathrm{kg})$ & Number of writhes & Inhibition of writhing (\%) \\
\hline Negative control & & $75 \pm 7.1$ & \\
MEAE & 100 & $49.9 \pm 5.9$ & 33.46 \\
MEAE & 200 & $37.8 \pm 4.3$ & 49.6 \\
MEAE & 400 & $33.1 \pm 4.6$ & 55.86 \\
Standart aspegic & 100 & $27.7 \pm 3.7$ & 63.06 \\
\hline
\end{tabular}

\section{Figures}



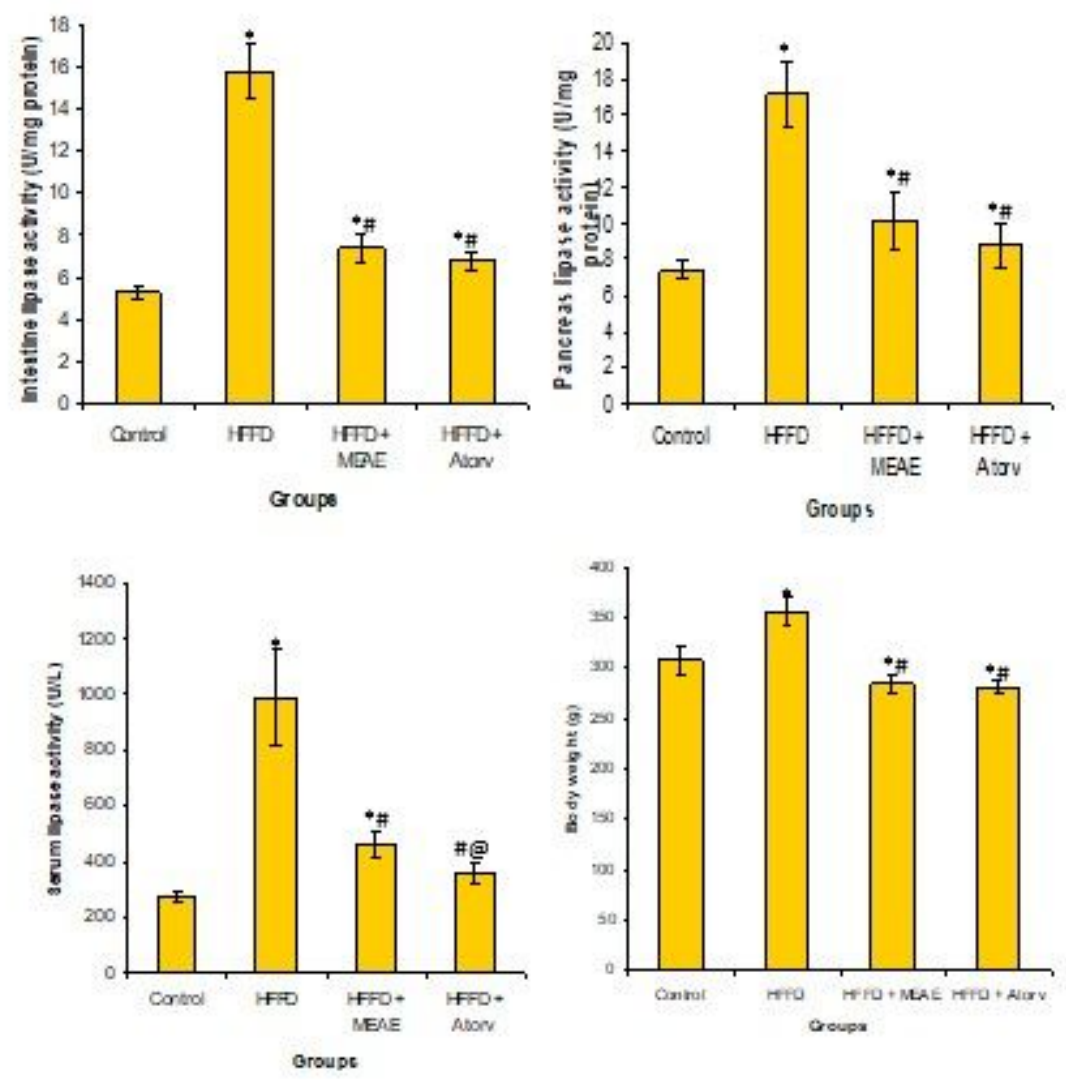

\section{Figure 1}

Intestine, pancreas and serum lipase activity; body weight and food intake in HFFD-rats treated with MEAE. Values are given as mean \pm SD for groups of 8 animals each. The values are statistically presented as follows: * ${ }^{\star}<0.05$ vs. controls at day $(0)$. $\# p<0.05$ vs. controls at day( 90$)$. @p $<0.05$ vs. untreated HFFD-rats. 

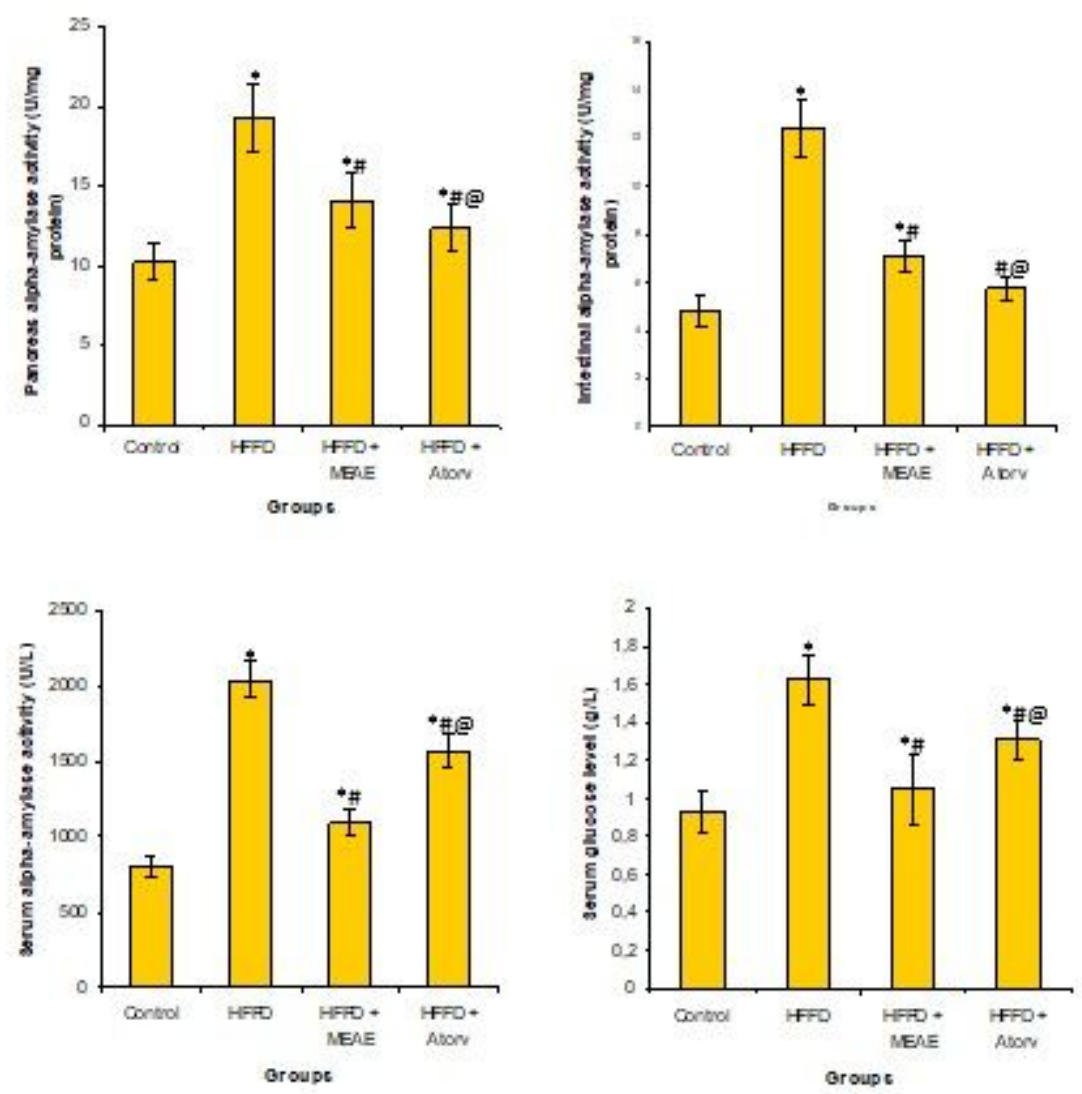

\section{Figure 2}

Intestine, pancreas and serum a-amylase activity; and blood glucose level in HFFD-rats treated with MEAE. Values are given as mean \pm SD for groups of 8 animals each. The values are statistically presented as follows: * $p<0.05$ vs. controls at day $(0)$. $\# p<0.05$ vs. controls at day $(90)$. @p $<0.05$ vs. untreated HFFD-rats. 